\title{
Web 2.0: What Is It And Is It For Me?
}

Katharine A. Bohley, University of Indianapolis, USA

\begin{abstract}
This article will define Web 2.0 and determine if it is "right" for you. The author has been teaching with technology for over ten years and has identified Web 2.0 categories that are emerging in higher educational institutions. A summary of seven categories of the "Education Winners" as well as a comparison of each of the winners will be provided. After reading this article, one should be able to determine if Web 2.0 tools might be of interest to them in using in order to promote learning in the classroom. Moreover, the reader will be able to determine what tools are of interested to them in order to determine where the starting point should be for them and their students.
\end{abstract}

Keywords: Web 2.0, Social Bookmarking, Start Pages, Aggregators, Teaching, Learning, Technology

\section{WHAT IS WEB 2.0?}

$\mathbb{Q}$ ccording to Tim O'Reilly's, "Web 2.0 applications are those that make the most of the intrinsic advantages of that platform: delivering software as a continually-updated service that gets better the more people use it, consuming and remixing data from multiple sources, including individual users, while providing their own data and services in a form that allows remixing by others, creating network effects through an "architecture of participation," and going beyond the page metaphor of Web 1.0 to deliver rich user experiences". if you are not a technological advanced it is challenging to truly understand the meaning of Web 2.0. Web 2.0 tools help people build online communities for creativity, collaboration, and sharing. There are numerous categorizes of Web 2.0 Tools. The most comprehensive list of WEB 2.0 tools is provided by SEOmoz, a company provides expertise to others around the world with consulting, Internet marketing and search engine optimization services. SEOmoz is infamous for providing its annual Web 2.0 awards categorized in 41 categories. Categories range from bookmarking to widgets and everything in between. A comprehensive list of the 2008 award winners can be found on the SEOmoz website; however, list Web 2.0 tools that have been implemented with success in the classroom are listed in Table 1. ${ }^{\mathrm{ii}}$ The seven categories that are of educator need to consider when determining how to implement technology into the classroom are: (1) Bookmarking, (2) Books, (3) Collaborative Writing and Word Processing, (4) Education, (5) Hosted Wikis, (6) News and Blog Guides, and (7) Start Pages.

Table 1

Web 2.0: Educational Winners

\begin{tabular}{|l|l|l|l|}
\hline \multicolumn{1}{|c|}{ Category } & \multicolumn{1}{c|}{ 2st Place } & \multicolumn{1}{c|}{ 3rd Place } \\
\hline Bookmarking & Del.icio.us & StumbleUpon & Furl \\
\hline Books & Lulu & Biblio & VuFind \\
\hline $\begin{array}{l}\text { Collaborative Writing and } \\
\text { Word Processing }\end{array}$ & Google Docs & Writeboard & Thinkfree \\
\hline Education & .Docstoc & Mango Languages & SpanishPod \\
\hline Hosted Wikis & PBwiki & Wetpaint & Wikispaces \\
\hline News and Blog Guides & Google Blog Search & Bloglines & Technorati \\
\hline Start Pages & Netvibes & Pageflakes & iGoogle \\
\hline
\end{tabular}




\section{THE EDUCATIONAL WINNERS}

\section{Bookmaking}

Bookmarking is the storing, describing, and sharing Bookmarks through shared metadata. To create a collection of social bookmarks, one must register with a social bookmarking site, which lets you store bookmarks, add tags of your choice, and designate individual bookmarks as public or private. All of the social bookmarking winners allows a place for educators to collect web resources and make it available to others. Faculty are creating accounts and sharing them with students and peers and students are using bookmarking to share with other students. Del.icio.us and Furl are becoming are more popular than StumbleUpon with regard to higher education.

\section{Books}

There are three distinct winners in the Book category. The first place winner, Lulu, provides a platform for educators to publish their material without dealing with publishers and to browse others material. Obviously, there are issues with regard to promotion and tenure for faculty to publish their material on this website. Some higher education institutions are addressing these types of issue with regard to the promotion and tenure guidelines; however, there has not been much movement in this area. On the other hand, the second place winner, Biblio, allows educators to search for rare books that might be out of date for publication. Biblio is useful for a few departments in higher education, but it is not used in the mainstream. VuFind, the third place winner in this Book category, is worthy of noting due to the long term impact of having an open source software that assist in digitizing the traditional library catalog.

\section{Collaborative Writing and Word Processing}

Google online document management is a well-known platform to create, store and share documents at many higher education institutions, thus it only seems naturally for this freeware to be number one in this list. Wirteboard is a unique collaborative writing tool due to its ability to have an RSS feed to inform you of changes to the document. Both Google and Writeboard are being used by faculty and students. The third place winner, Thinkfree, is not as popular in higher education at this time.

\section{Education}

Two of the winners in the Education category are website that assists with learning another language. The third place winner, SpanishPod provides hundreds of lesson plans to assist in learning Spanish and it even links its users to native speakers. This is a fabulous tool for anyone wanting to learn Spanish. The second place winner, Mango, in the Education category is similar to SpansihPod, but it provides 12 different language courses. The first place winner, .Docstoc (dot-doc-stock), has nothing to do with learning another language, but rather it is a website that has numerous legal, educational, technical and business documents one can download for free. Moreover, one can upload their own files to .Docstoc (dot-doc-stock) in a number of formats.

\section{Hosted Wikis}

Wikis allows users to freely create and edit Web page content using any Web browser. Often times Wikis are used for discussion and can be private or public discussion. It seems that Wikis are the next generation of discussion boards and Wikis are a good source for collaboration and are becoming more popular in education. PBWiki, seems to be the most popular wiki for educators.

\section{News and Blog Guides}

A blog is similar to an online journal. It is not just the diary type journal. Many companies are using blogs to promote and inform others about their product or services. All of the winners in the News and Blog Guides can be used for student journaling or for the promotion of a specific department with higher educational institutions. 


\section{Start Pages}

All of the winners in this category, NetVibes, PageFlakes, and IGoogle, allow the user to create a personalized homepage with direct access to specific websites and they all offer the ability to use RSS feeds. The first place winner, NetVibes, is becoming more popular with educators because an educator can create a NetVibe page for a class and invite students to join.

\section{KEYS TO SUCCESS}

Even though the Web 2.0 Educational Winners have been introduced, it is necessity for an educator to realize that each of these "winners" must be analyzed in detail, as well as their course content, teaching style, and student's learning style in order for them to "winners" for them and their students. Regardless of what Web 2.0 tool one uses, there is not a comprehensive list to "guarantee success", but the following suggestions are helpful.

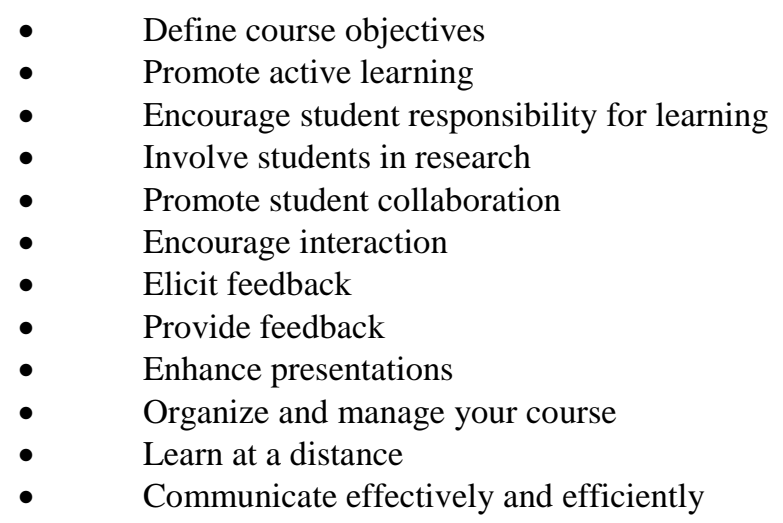

\section{CONCLUSION}

Develop an understanding of instructional technology paradigms and the various technologies available. Spend the majority of the preparation time determining what technology would best suit your course and teaching style. Organizing the course is the most challenging part of starting to teach online. Be sure to ask others for assistance. Once one has determined how to organize the course, it is time to discuss the concepts with individuals working in the computer department. After brainstorming with the technologist, it will be essential to revise the original plan. Depending on the amount of resources, it could be as easy as delegating the work. However, if one's institution resources are limited and a technologist is not available, faculty can be creative in finding resources via student workers or providing internship credit for students.

\section{AUTHOR INFORMATION}

Katharine A. Bohley, an Associate Professor in the School of Business at University of Indianapolis, has been a leader in integrating emerging technologies into the classroom for over a decade. Dr. Bohley is actively encouraged her colleagues to utilize various technologies to enhance student learning. Katharine has been able to successfully teach various levels of students, from high school students to graduate students, in the areas of International Business and International Marketing with the implementation of Web 2.0 into her teaching.

\section{REFERENCES}

1. O'Reilly, T. (2005). What Is Web 2.0-Design Patterns and Business Models for the Next Generation of Software.

2. SEMoz. (n.d.). Retrieved from http://www.seomoz.org/web2.0/short

i (O'Reilly, 2005)

ii (SEMoz) 


\section{NOTES}

